\title{
Preoperative histologic diagnosis of chest wall invasion by lung cancer using ultrasonically guided
}

biopsy

Before operation, we evaluated the usefulness of ultrasonically guided needle biopsy to detect histologically invasion of the chest wall by tumor in patients with lung cancer. Ultrasonically guided needle biopsy, computed tomography, and ultrasonography were done in 29 patients with lung cancer. In all of them, chest wall invasion was histologically confirmed by thoracotomy. As for the diagnosis of chest wall invasion, sensitivity, specificity, and accuracy of ultrasonically guided needle biopsy diagnosis were $61.5 \%, 100 \%$, and $82.8 \%$, respectively; for diagnosis by computed tomographic scan these figures

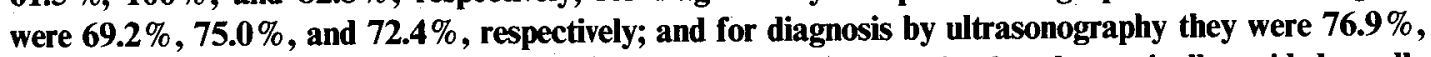
$68.8 \%$, and $72.4 \%$, respectively. We had no false-positive cases in the ultrasonically guided needle biopsy assessment and no fatal complications or implantation metastases. Our results indicate that ultrasonically guided needle biopsy is safe and useful for preoperative histologic diagnosis of chest wall invasion in cases in which combined chest wall resection is being considered in patients with lung cancer. (J THORAC CardiovasC Surg 1994;107:891-5)

Noboru Nakano, MD, ${ }^{\mathrm{a}}$ Tsutomu Yasumitsu, MD, ${ }^{\mathrm{b}}$ Yahiro Kotake, MD, ${ }^{\mathrm{b}}$ Hideo Morino, MD, ${ }^{\mathrm{c}}$ and Junpei Ikezoe, MD, ${ }^{\mathrm{d}}$ Shigenobu and Habikino, Japan

T he chest wall is involved by direct tumor extension in approximately $8 \%$ of patients undergoing thoracotomy for lung cancer. ${ }^{1,2}$ Extrapleural resection or combined en bloc chest wall resection can be done with an expected 5 -year survival in more than $50 \%$ of patients in the absence of lymphatic metastases. ${ }^{3}$ Some reports have suggested that computed tomography $(\mathrm{CT})$ is inaccurate in assessing chest wall invasion in patients with peripheral pulmonary neoplasms. ${ }^{47}$ If chest wall invasion could be diagnosed histologically before thoracotomy, it would be useful in determining the surgical methods to be used.

In this report, ultrasonically guided needle biopsy (UGB) is prospectively evaluated to determine whether chest wall invasion is present in patients with lung cancer.

From the Department of Surgery, Ehime National Hospital, ${ }^{\text {a Shigeno- }}$ bu, Ehime; the Departments of Surgery ${ }^{\mathrm{b}}$ and Pathology, ${ }^{\mathrm{c}}$ Osaka Prefectural Habikino Hospital, Habikino City, Osaka Prefecture; and the Department of Radiology, ${ }^{d}$ Osaka University Medical School, Suita City, Osaka, Japan.

Received for publication Jan. 13, 1993.

Accepted for publication Aug. 17, 1993.

Address for reprints: Noboru Nakano, MD, 366, Yokogawara, Shigenobu-cho, Onsen-gun, Ehime, 791-02, Japan.

Copyright ( 1994 by Mosby-Year Book, Inc.

$0022-5223 / 94 \$ 3.00+0 \quad 12 / 1 / 50821$

\section{Patients and methods}

One hundred and seventy-six patients with lung cancer, including five metastatic lung cancers, underwent preoperative ultrasonography and thoracotomy at the Department of Surgery, Osaka Prefectural Habikino Hospital, between October 1984 and September 1987. Forty-six patients were found to have peripheral lung tumors adjacent to the chest wall on the preoperative ultrasonograms. Seven patients refused to have UGB done, and 39 patients agreed to the procedure. In six of these, the biopsy specimens were composed of only chest wall tissue, in three only of lung tumors, and in one only of lung tissue. The status of chest wall invasion in these 10 patients could not be histologically evaluated by UGB, and they were excluded in data analysis. Thus in 29 patients the presence or absence of chest wall invasion could be histologically evaluated.

The product of the largest diameter (in centimeters) and the depth (in centimeters) of the lung tumor assessed by ultrasonography was calculated. The mean \pm the standard deviation of the product of the tumor dimensions for the excluded 10 patients was $11.3 \pm 6.5$ and that of the tumor for the 29 patients included in this study was $24.0 \pm 20.8$. There were significant differences between the two groups ( $t$ test, $p<0.01$ ).

The 29 patients underwent CT scanning and ultrasonographic examination before thoracotomy. The study population consisted of 25 men and 4 women with a mean age of 65.4 years, ranging from 47 to 79 . There were 26 cases of primary lung cancer and three of metastatic cancer originating from rectal, colon, and uterine cancers.

CT scanning with a GE-YMS CT 8600 scanner (Yokogawa Co., Ltd., Tokyo, Japan) was done by contiguous sectioning (10 


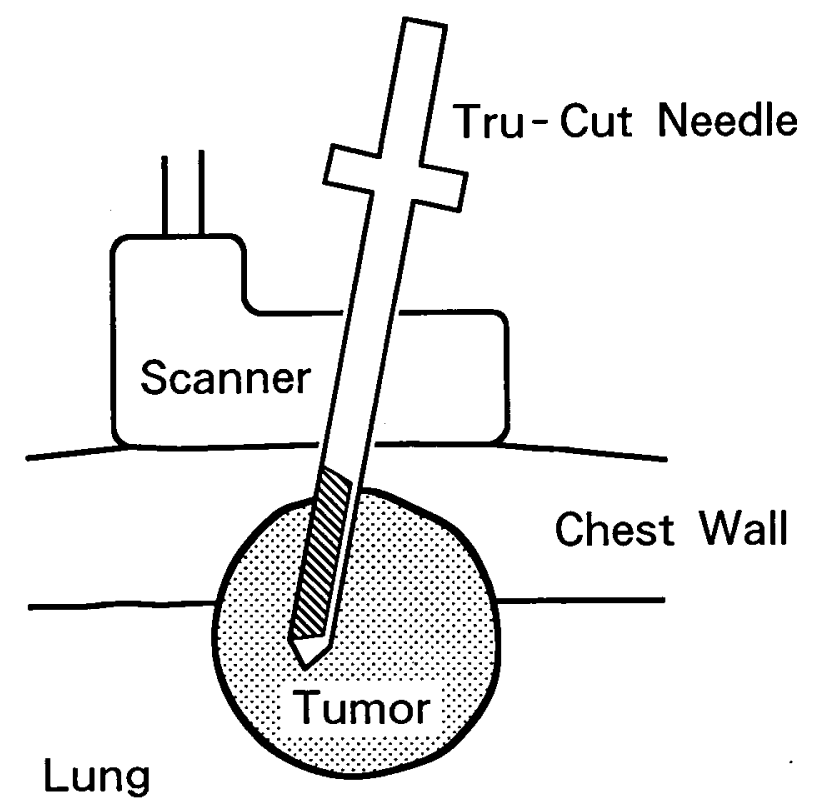

Fig. 1. Schematic representation of technique of UGB for histologic diagnosis of chest wall invasion.

$\mathrm{mm}$ thick) from the pulmonary apex to the base. The CT criteria used to evaluate possible chest wall invasion were (1) an unclear inner surface of the chest wall adjacent to the mass and (2) an obliterating fatty plane of the chest wall. ${ }^{8}$

An ultrasonic unit (SSD-256, Aloka Co., Ltd., Tokyo, Japan) connected to a linear probe (UST-5024C, 3.5 MHz, Aloka) was used for the ultrasonic examination before UGB. The criteria used to evaluate possible chest wall invasion were (1) irregularity, thickness, or discontinuity of the parietal pleura and (2) lack of respiratory movement of the mass. ${ }^{9}$

The same ultrasonic unit connected to a linear probe (UST$507 \mathrm{BP}, 3.5 \mathrm{MHz}$, Aloka), which was provided with a central guided channel for needle introduction, was used for UGB. A Tru-Cut biopsy needle (14 gauge, Travenol Laboratories, Inc., Deerfield, Ill.) was used for cutting-needle biopsy. While the echo from the needle tip was monitored with the ultrasonic unit, the position where the mass was considered by ultrasonography to extensively invade the chest wall was selected for biopsy (Fig. 1). The specimen was placed on filter paper and fixed in $10 \%$ formalin so that it retained its shape. The needle biopsy was done once or twice in each patient with different needles. The specimen was stained with hematoxylin and eosin and elastic-van Gieson stains and was histologically examined. A pathologist examined the resected tumor to determine whether or not there was chest wall invasion, including parietal pleural invasion (Fig. 2).

Sensitivity, specificity, and overall accuracy of the diagnoses were calculated by the formulas of Feinstein. ${ }^{10}$

\section{Results}

Histologic examination of the resected specimens revealed that 13 lung tumors invaded the chest wall, three of which did not extend beyond the parietal pleura, and that 16 patients had no chest wall invasion.
Table I. Comparison of the results for CT scanning, ultrasonography, and UGB in the assessment of chest wall invasion of lung cancer

\begin{tabular}{lccc}
\hline \multicolumn{1}{c}{$C T$} & & \\
Diagnosis & scanning & Ultrasonography & UGB \\
\hline True positives & 9 & 10 & 8 \\
False positives & 4 & 5 & 0 \\
True negatives & 12 & 11 & 16 \\
False negatives & 4 & 3 & 5 \\
Sensitivity (\%) & 69.2 & 76.9 & 61.5 \\
Specificity (\%) & 75.0 & 68.8 & 100 \\
Accuracy (\%) & 72.4 & 72.4 & 82.8 \\
\hline
\end{tabular}

Table I shows the result of the assessment of chest wall invasion by UGB, ultrasonography, and CT scan in 29 patients. Correct diagnosis of positive chest wall invasion by UGB was obtained in 8 of 13 patients. There were four and five cases, respectively, of false-positive results with CT scanning and ultrasonographic assessment. There was no histologic chest wall invasion in the resected specimens when ultrasonography showed respiratory movement of lung tumor. We had no false-positive results in the UGB assessment, but there were five cases of false-negative results in the diagnoses by UGB. Because in these cases the specimens obtained were not from the most deeply invasive site, three lung tumors were biopsied diagonally and two tumors were biopsied through atelectatic lung tissue. The sensitivity, specificity, and accuracy of UGB were $61.5 \%, 100 \%$, and $82.8 \%$, respectively; those figures for CT diagnosis were $69.2 \%, 75.0 \%$, and $72.4 \%$, respectively; and for ultrasonographic diagnosis $76.9 \%$, $68.8 \%$, and $72.4 \%$, respectively.

Eight patients in whom UGB diagnosis had been positive for chest wall invasion were treated with en bloc resection (in six) or extrapleural resection (in two). Five patients, $17.2 \%$ of all patients, in whom false-negative chest wall invasion had been diagnosed in the UGB assessment, were treated with en bloc resection (in three) or with extrapleural resection (in two), because chest wall invasion was determined to be positive during the operation. Two unnecessary chest wall resections were done on the basis of CT scan, ultrasonographic, and intraoperative diagnoses, negative chest wall invasion had been shown in the UGB assessment and was proved negative on the histologic examination (Fig. 3).

As for complications of UGB, there were four cases of hemoptysis and one case of hemothorax, which did not require any treatment. No dissemination of the malignant cells was found at the thoracotomy on the histologic examination of resected lung in any case, nor had there been chest wall implantation metastasis at the biopsy sites, as examined by palpation and chest $\mathrm{x}$-ray film, until 


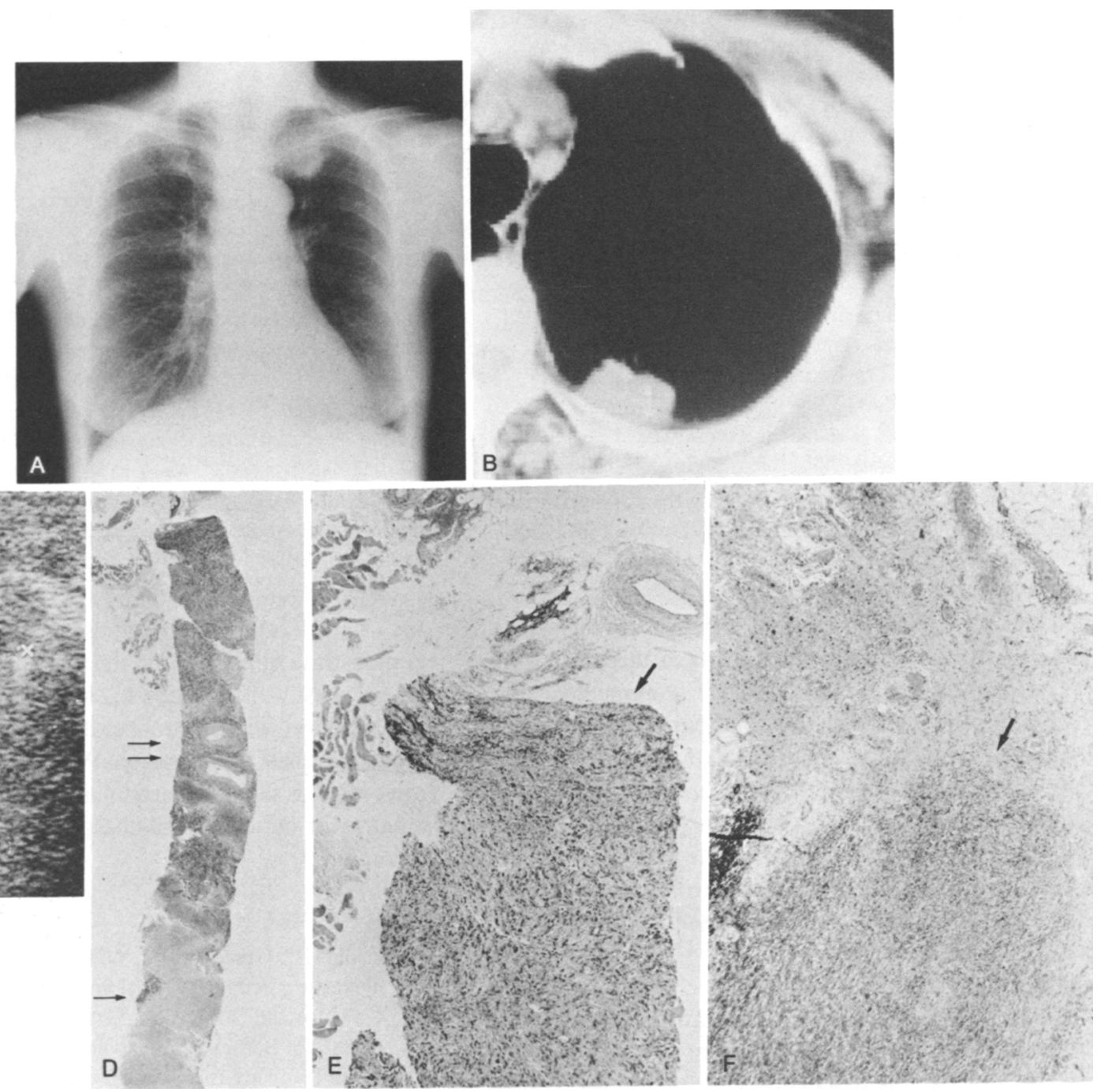

Fig. 2. Bronchogenic carcinoma in 61-year-old woman. A, Chest radiograph shows solitary mass in left upper lobe. B, CT scan shows mass adjacent to posterior chest wall. Fatty plane of chest wall is obliterated. C, Ultrasonograph demonstrates irregular surface of parietal pleura and lung tumor (between $X$ and $x$ ) without respiratory movement. D, Photomicrograph of biopsy specimen, which is about $1.5 \mathrm{~mm}$ in diameter and $15 \mathrm{~mm}$ long and consists of lung (arrow) and adhered pleura (double arrow) (hematoxylin and eosin stain, original magnification $\times 4$ ). E, High-power view of $\mathbf{D}$ showing adenocarcinoma (arrow) invading fatty tissue just outside parietal pleura (hematoxylin and eosin stain, original magnification $\times 13$ ). F, Photomicrograph of surgical specimen demonstrates adenocarcinoma (arrow) invading fatty tissue outside partial pleura (hematoxylin and eosin stain, orignial magnification $\times 13$ ).

June 1993, excluding missing one. There were no fatal complications in this series.

\section{Discussion}

There is a great deal of controversy regarding the use of CT scanning to assess chest wall invasion in patients with lung cancer. ${ }^{47,11}$ This might be because the criteria used in evaluating the CT scan results have been different from one another. At present, especially in cases in which minimal invasion or inflammatory adhesion is the problem, it may be difficult to reach an agreement as to which criterion should be applied when assessing chest wall invasion by $\mathrm{CT}$ scan.

Igarashi and associates ${ }^{9}$ have reported the accuracy of the diagnosis of chest wall invasion with ultrasonography as being $61 \%$ and suggested that there was a tendency to underestimate the invasion when sufficient acoustic window could not be secured. In the present study, we believe 


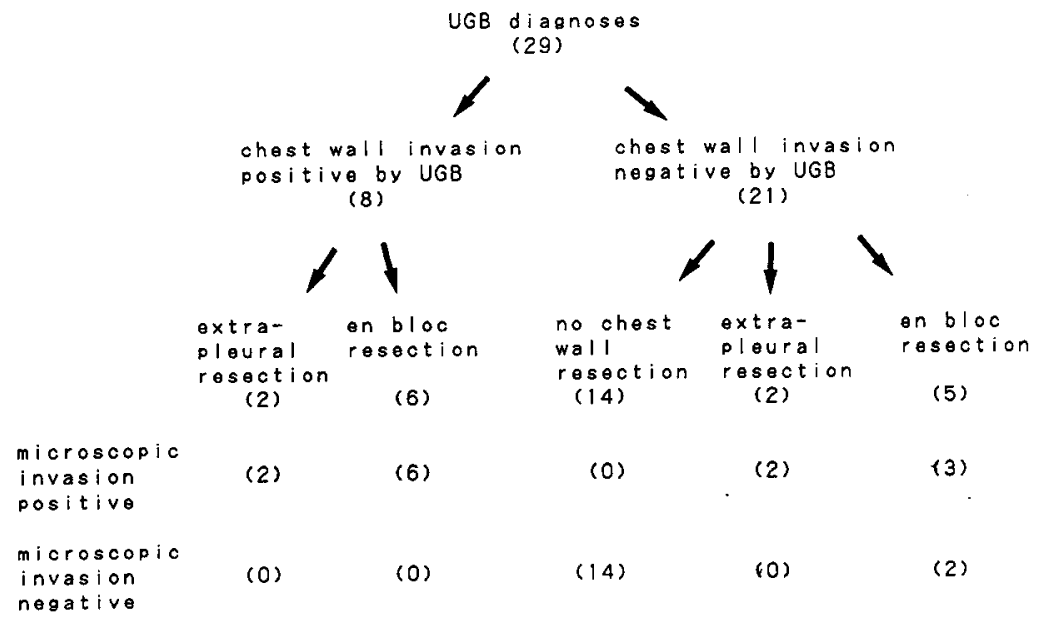

Fig. 3. Flow diagram describing the number of patients in the study divided according to diagnosis by UGB, operative methods, and microscopic chest wall invasion.

that UGB may be unnecessary when ultrasonography shows respiratory movement of the lung tumor.

Trastek, Pairolero, and Piehler ${ }^{12}$ commented that when adherence of the visceral and parietal pleuras was discovered at operation, whether inflammatory or malignant, the case was most difficult to manage intraoperatively. It has been reported that from $14 \%$ to $37 \%$ of the patients in whom chest wall invasion was diagnosed during the operation underwent combined chest wall resection, although chest wall invasion was found to be negative on the histologic examination. ${ }^{13,14}$ Combined chest wall resection reportedly results in operative mortality in $3 \%$ to $16 \%$ of the cases. ${ }^{15-17}$ Preoperative diagnosis with CT scan or ultrasonography and intraoperative diagnosis may be unavoidably associated with unnecessary chest wall resection.

Radiologically, ultrasonically, and CT-guided punctures have allowed the application of less harmful and more successful biopsy of lung tumors. Ikezoe, Morimoto, and Kozuka ${ }^{18}$ reported that UGB was recommended rather than CT-guided biopsy, because CT-guided biopsy lacked the real-time monitoring and had a high incidence of complications.

Sinner ${ }^{19}$ has reported that only one patient in his series comprising 2726 patients who underwent needle biopsy was found to have an implantation metastasis 5 months after needle biopsy. We have not had such a case in 28 patients, excluding missing one.

CT scan and ultrasonographic diagnoses are based on the images, but UGB assessment is of histologic diagnosis, which allows no false-positive results that inevitably lead surgeons to resect the chest wall. However, UGB diagnoses did have five false-negative cases, accounting for $17.2 \%$ of total UGB diagnoses. Even if UGB does not demonstrate tumor beyond the visceral pleura, we should do the chest wall resection to obtain an adequate margin at that level when intraoperative diagnosis is positive regarding chest wall invasion. We conclude that preoperative UGB is safe and particularly useful for determining whether or not combined chest wall resection should be done.

\section{REFER E N C ES}

1. Grillo HC, Greenberg JJ, Wilkins EW. Resection of bronchogenic carcinoma involving the thoracic wall. J THORAC CARDIOVASC SURG 1966;51:417-21.

2. Geha AS, Bernatz PE, Wooiner LB. Bronchogenic carcinoma involving the thoracic wall: surgical treatment and prognostic significance. J THORAC CARDIOvasc SURG 1967;54:394-401.

3. McCaughan BC, Martini N, Bains MS, McCormack PM. Chest wall invasion in carcinoma of the lung: therapeutic and prognostic implications. J THORAC CARDIOVASC SURG 1985;89:836-41.

4. Ekholm S, Albrechtsson U, Kugelberg J, Tylen U. Computed tomography in preoperative staging of bronchogenic carcinoma. J Comput Assist Tomogr 1980;4:763-5.

5. Baron RL, Levitt RG, Sagel SS, White MJ, Roper CL, Marbarger JP. Computed tomography in the preoperative evaluation of bronchogenic carcinoma. Radiology 1982; 145:727-32.

6. Rendina EA, Bognolo DA, Mineo TC, et al. Computed tomography for the evaluation of intrathoracic invasion by lung cancer. J THORAC CARDIOVASC SURG 1987;94:57-63.

7. Pennes DR, Glazer GM, Wimbish KJ, Gross BH, Long $\mathrm{RW}$, Orringer MB. Chest wall invasion by lung cancer: limitations of CT evaluation. AJR Am J Roentgenol 1985; 144:507-11. 
8. Higashihara T, Sone S, Ikezoe J, et al. CT evaluation for the diagnosis of pleural invasion of primary lung cancer. $J$ Jpn Radiol Soc 1983;43:743-9.

9. Igarashi T, Takahashi Y, Mori M, Suzuki A, Kusajima K, Muroya K. Imaging diagnosis for the pleural invasion of primary lung cancer: a comparison between CT and US diagnosis. J Med Imag 1984;4:937-44.

10. Feinstein AR. On the sensitivity, specificity and discrimination of diagnostic tests. In: Feinstein AR, ed. Clinical biostatistics. St. Louis, Mo.: Mosby, 1977:214-6.

11. Willford ME, Hidalgo H, Putman CE, Korobkin M, Ram PC. Computed tomography of pleural disease. AJR Am J Roentgenol 1983;140:909-14.

12. Trastek VF, Pairolero PC, Piehler JM. En bloc (non-chest wall) resection for bronchogenic carcinoma with parietal fixation. J THORAC CARDIOvasC SuRG 1984;87:352-8.

13. Mishina H, Suemasu K, Yoneyama T, et al. Surgical pathology and prognosis of the combined resection of chest wall and lung in lung cancer. Jpn J Clin Oncol 1987;8:1618.
14. Tsuyuguchi M. Clinicopathological studies on bronchogenic carcinoma involving thoracic wall: with special reference to prognosis after surgery. Haigun 1978;18:349-63.

15. Jamieson MPG, Walbaum PR, McCormack RJM. Surgical management of bronchial carcinoma invading the chest wall. Thorax 1979;34:612-5.

16. Paone JF, Spees EK, Newton CG, Lillemoe KD, Kieffer RF, Gadacz TR. An appraisal of en bloc resection of peripheral bronchogenic carcinoma involving the thoracic wall. Chest 1982;81:203-7.

17. Piehler JM, Pairolero PC, Weiland LH, Offord KP, Payne WS, Bernatz PE. Bronchogenic carcinoma with chest wall invasion: factors affecting survival following en bloc resection. Ann Thorac Surg 1982;34:685-91.

18. Ikezoe J, Morimoto S, Kozuka T. Sonographically guided needle biopsy of thoracic lesions. Semin Interv Radiol 1991; 8:15-22.

19. Sinner WN. Pulmonary neoplasms diagnosed with transthoracic needle biopsy. Cancer 1979;43:1533-40. 